I Universidade Federal Fluminense (UFF), Programa de Pós-Graduação em

Sociologia, Niterói, Rio de Janeiro, Brasil

lcfridman@globo.com

https://orcid.org/0000-0002-9730-445I

Luis Carlos Fridman'

\title{
THEODOR ADORNO E ERIC HOBSBAWM SOBRE O JAZZ
}

Em gravações de "Samba da minha terra", Dorival Caymmi e João Gilberto cantavam: "Quem não gosta do samba/Bom sujeito não é/É ruim da cabeça/Ou doente do pé". Algo dessa ordem pode ser creditado ao prestígio mundial do jazz. Apesar de suas obras não ocuparem os primeiros lugares nas listas de vendagens e nas paradas de sucessos, músicos e intérpretes de diversos gêneros o consideram um domínio nobre da criação artística. No entanto, não foi essa a percepção de Theodor Adorno em sua severa crítica do jazz, associando-o à regressão auditiva e ao conformismo social. As objeções de Adorno não se pautaram apenas pela resistência ao som dançável das big bands que encantava as plateias e produzia frisson nos salões. O filósofo alemão ostentava sólida formação musical e questionou a própria estrutura formal do jazz, considerado uma diluição da grande tradição da música clássica ou mesmo dos arrojos de vanguarda. Para ele, o gênero havia sido capturado pela indústria cultural por meio da "estandardização" e da padronização de trilhas e arranjos que satisfaziam o gosto estético ancorado nos confortos do "mesmo". O historiador Eric Hobsbawm, um aficionado do jazz, viu nele a música por excelência da sociedade industrial moderna e expressão privilegiada de raízes culturais populares. Ao contrário de Adorno, os estudos e a vivência de Hobsbawm nos ambientes jazzísticos realçam a expansão das fronteiras da música popular e novas formas de "erudição", dessa vez acessíveis à massa dos subalternos. No cotejamento desses argumentos contrastantes, tentarei esmiuçar aspectos que revelam a importância do jazz como linguagem artística no quadro da cultura musical contemporânea. 
Theodor Wiesengrund-Adorno nasceu em um ambiente musical. Sua mãe era cantora lírica profissional, o que certamente influenciou seus estudos de composição com Alban Berg, autor de óperas e peças de câmera, vinculado à escola de pensamento musical de Viena, que tinha como expoentes Arnold Schoenberg e Anton Webern. Nos anos I920, Adorno compôs obras para piano e quartetos de cordas e, inclinado às experiências de vanguarda, aproximou-se do atonalismo.

Adorno escreveu profusamente sobre a criação e a atividade musical em textos como "A situação social da música", "On jazz", "Sobre o caráter fetichista da música e a regressão da audição", "Fragmentos sobre Wagner" e "Sobre música popular", entre outros. Mediante o conceito de indústria cultural, de base marxista, abrangeu a produção das mercadorias artísticas e de seu consumo no ambiente constituído pela "autoridade ditatorial do sucesso comercial" (Adorno, I980: I68). Em sua caracterização, Adorno associou o jazz à "arte comercial ligeira", qualificando-o como um gênero que conduzia os ouvintes à regressão da audição, isto é, à perda da liberdade de escolha e da capacidade de conhecimento consciente da música, além da escuta atomística e a dissociação.

O historiador marxista Eric J. Hobsbawm durante um largo período colaborou com o jornal inglês New Statesman, como crítico de jazz, sob o pseudônimo de Francis Newton (em homenagem ao trompetista Frankie Newton). Escreveu História social do jazz e Pessoas extraordinárias - resistência, rebelião e jazz, cuja terceira parte é dedicada ao jazz nos ensaios "O Caruso do jazz", "Count Basie", "O Duke”, "O jazz vai à Europa”, "O swing popular", "O jazz a partir de I960" e "Billie Holiday”. Na "Introdução à edição de I989" de História social do jazz, Hobsbawm confere a esse gênero o tratamento de "um dos fenômenos mais significativos da cultura mundial do século XX [...] e as razões para seu extraordinário apelo, tanto nos EUA quanto em outros lugares" (Hobsbawm, 2009: I 2). Ou ainda como "uma realização extraordinária, um aspecto marcante da sociedade em que vivemos" (Hobsbawm, 2009: 3I), em nada semelhante a uma música de caráter eminentemente comercial, regressiva e conformista. Hobsbawm afirma que a presença do jazz no mercado fonográfico não diluiu as suas inovações, nem seu rico significado cultural.

A extensa pesquisa histórica de Hobsbawm revela aspectos fundamentais que escaparam às formulações de Adorno, especialmente no que diz respeito à complexidade da linguagem do jazz e de seus vínculos com as experiências do povo negro na América. O debate em torno da autenticidade e originalidade do jazz ou, no seu oposto, da instrumentalização, manipulação e enlevo superficial não obscurece a abrangência e a fertilidade do conceito de indústria cultural. No entanto, o jazz se mostrou um gênero musical que não produziu o "rebaixamento do gosto estético" e esteve longe de alimentar apenas satisfações conformistas. 


\section{O OUVIDO “INFANTIL” E A MÚSICA DAS MERCADORIAS}

Segundo Adorno, as obras da música erudita de vanguarda lidam com o fracionamento da vida cotidiana no capitalismo por escapar do conforto e da passividade do "sempre igual". A vanguarda teria ultrapassado os limites estabelecidos pela indústria cultural em contraste com a "música ligeira", do campo da música popular, associada à "disseminação de bens padronizados para a satisfação de necessidades iguais" (Adorno \& Horkheimer, I985: I I4), como se lê no ensaio "A indústria cultural: o esclarecimento como mistificação das massas", de Dialética do esclarecimento.

A produção da música para ser consumida em massa traz a exigência do sucesso e da pasteurização, que implicam a regressão da audição, definida por Adorno em termos psicanalíticos como o estado infantil de docilidade e abdicação da vontade livre e racional do ouvinte que estranha ou recusa o novo e o não familiar. O que é ouvido repetidamente nos meios de comunicação de massa influi para a afirmação de um gosto estimulado pela profusão de arranjos diluidores chamados de produções-padrão (Adorno, I980: I7I). Em "O fetichismo na música e a regressão da audição", Adorno (I980) caracteriza a regressão como a aceitação passiva do idêntico e do repetitivo, que impede escolhas na direção de um horizonte mais amplo:

A repressão efetua-se em relação a essa possibilidade presente; mais concretamente, constata-se uma regressão quanto à possibilidade de outra música, oposta a essa. Regressivo é, contudo, também o papel que desempenha a atual música de massas na psicologia de suas vítimas. Esses ouvintes não somente são desviados do que é mais importante, mas confirmados na sua nescidade neurótica, independentemente de como as suas capacidades musicais se comportam em relação à cultura especificamente musical de etapas sociais anteriores (Adorno, I980: 180).

Não é prudente minimizar a complexidade do argumento de Adorno, atribuindo-lhe apenas juízos exteriores ao exame das linguagens com alcance de massa. Seus conhecimentos sólidos de composição melódica e instrumental permitem identificar o fetichismo na própria estrutura interna dessas soluções musicais pela prática disseminada dos arranjos que "separa manifestamente os 'achados' (ideias criadoras), coisificados e os arranca de seu contexto musical, montando-os num pot-pourri” (Adorno, I980: 175). A operação mais frequente dos arranjadores é a de "enfeitar" ou montar elementos isolados das obras (ou mesmo conjugá-los) e tornar o produto musical assimilável aos ouvintes regressivos. A deformação se faz pelo exagero, que Adorno (I980: 176) chama de colorística, e desfaz o "encantamento dos sentidos que deles se exige", presente nas grandes obras. Por oposição, em Haydn e Beethoven, "a sobriedade colorística tem uma profundíssima relação com a preponderância do princípio construtivo sobre os elementos melódicos individuais e isolados, que ressaltariam em cores brilhantes a partir da unidade dinâmica do conjunto" (Adorno, 
I980: I76). Os "momentos isolados de encantamento" aprisionam o ouvinte e impedem a elevação da audição:

O prazer do momento e da fachada de variedade transforma-se em pretexto para desobrigar o ouvinte de pensar no todo, cuja exigência está incluída na audição adequada e justa; sem grande oposição, o ouvinte se converte em simples comprador e consumidor passivo. Os momentos parciais já não exercem função crítica em relação ao todo pré-fabricado, mas suspendem a crítica que a autêntica globalidade estética exerce em relação aos males da sociedade. A unidade sintética é sacrificada aos momentos parciais, que já não produzem nenhum outro momento próprio a não ser os codificados, e mostram-se condescendentes a estes últimos. Os momentos de encantamento demonstram-se irreconciliáveis com a constituição imanente da obra de arte, e esta última sucumbe àqueles toda vez que a obra artística tenta elevar-se para a transcendência. Os referidos momentos isolados de encantamento não são reprováveis em si mesmos, mas tão somente na medida em que cegam a vista. Colocam-se a serviço do sucesso, renunciam ao impulso subordinado e rebelde que lhes era próprio, conjuram-se para aprovar e sancionar tudo o que um momento isolado é capaz de oferecer a um indivíduo isolado, que há muito tempo já deixou completamente de existir. Os momentos de encanto e de prazer, ao se isolarem, embotam o espírito (Adorno, I980: I68).

A fascinação de momento (instruída previamente pela repetição, difundida pela indústria cultural) indica o triunfo da alienação. Por oposição, o convite musical à escuta não domesticada alcança mais do que encantamentos efêmeros e amplia a experiência estética, "como se na arte os valores dos sentidos não fossem portadores dos valores do espírito, que somente se revela e se degusta no todo, e não em momentos isolados da matéria artística" (Adorno, I980: I68). O argumento se dirige à música ligeira, aquela de prazeres breves codificados em soluções repetitivas adequadas ao mercado e que não vinculam a parte com o todo para ultrapassar o consumo passivo:

A arte considera negativa precisamente aquela possibilidade de felicidade, à qual se contrapõe hoje a antecipação apenas parcial e positiva da felicidade. Toda arte ligeira e agradável tornou-se mera aparência e ilusão: o que nos antolha esteticamente em categorias de prazer já não pode ser degustador; a promesse du bonheur foi assim que uma vez se definiu a arte - já não se encontra em lugar algum, a não ser onde a pessoa tira a máscara da falsa felicidade (Adorno, I980: I68).

A arte ligeira, por ser agradável, alimenta a "ilusão" e a "falsa felicidade" e não exerce o papel dialeticamente negativo de possibilidades projetadas. A "autoridade ditatorial do sucesso comercial" incide sobre a estrutura da criação musical e desvanece a possibilidade de aproximar os indivíduos da transcendência. No universo da música séria essa consideração esteve presente na reflexão de Adorno acerca das diferenças entre Schoenberg e Stravinsky. Entusiasta da linguagem musical de Schoenberg, lançada nos espaços da atonalidade, Ador- 
no desenvolveu uma visão crítica de Stravinsky por suas concessões à tonalidade que facilitavam a audição, apesar do lugar garantido do compositor russo na vanguarda da música europeia. Em clara distinção com a música que alcança o sucesso comercial, Adorno (I980: I69) prossegue: "A música de Schoenberg, tão diferente das canções de sucesso, apresenta em todo caso uma analogia com elas: não é degustada, não pode ser desfrutada". A obra de Schoenberg não se presta à colorística dos arranjos nem se torna um produto assimilável pela publicidade e pelos meios de comunicação de massa. Por afugentar a escuta fácil, convida o ouvinte a penetrar um terreno que solicita reflexão e interpretação. Em "As duas faces da indústria cultural", que faz parte do compêndio Weber, Frankfurt - teoria e pensamento social I, Gabriel Cohn (20I7: 249-250) esclarece os fundamentos de tal reflexão e as dimensões cognitivas aí implicadas:

A ideia envolvida é a de que, ao contrário do mero entretenimento, o contato com a obra de arte é uma atividade produtiva ao seu modo, que requer um investimento, consciente e, portanto, potencialmente racional, de esforço de todas as dimensões da percepção, incluindo a cognitiva. Na realidade, está em jogo a ideia, só realizável no limite, de uma experiência de contato ativo com a obra de arte, em contraste com a mera fruição passiva que, também no limite, caracteriza o entretenimento e, por extensão, todas as modalidades de produtos da indústria cultural.

Na música séria cada momento se vincula ao desenvolvimento integral da composição, o todo, e permite a experiência crítica que transtorna os confortos do mesmo. A música ligeira traz a supressão da possibilidade de estremecer o conhecido e obstrui o avanço dos limites do sensível em outras direções que não o sempre igual. Os enlevos da música ligeira dispensam a atenção concentrada e reproduzem a parcialidade vivida nas relações sociais.

Ao rebater ideias então correntes de que a massificação poderia fornecer a força coletiva e a base de sensibilização que permitiria voos mais altos, Adorno não admitia continuidade possível entre a música séria e a música ligeira. Nesse quadro entendeu o jazz como "música de fundo", ou seja, uma forma musical ligeira que não favorecia a reflexão sobre a experiência. O jazz e as canções de sucesso, "em sua despreocupada simplicidade da música", carregavam distorções dos "genuínos valores da cultura" (Adorno, I980: I69). Associou-o a um "estado de distração" em vez de a uma "audição concentrada" (Adorno, I980: I82):

O costumeiro jazz comercial só pode exercer a sua função quando é ouvido sem grande atenção, durante um bate-papo e sobretudo como acompanhamento de baile. De vez em quando se ouvirá a opinião de que o jazz é sumamente agradável num baile e horrível de ouvir.

Pela irredutibilidade da distinção entre música séria e música ligeira, atribuiu aos admiradores do jazz (e demais amantes da música popular) a "rejeição ignorante e orgulhosa de tudo o que sai do costumeiro" (Adorno, I980: I84), experiência estética que correspondia "ao comportamento do prisioneiro 
que ama a sua cela porque não lhe é permitido amar outra coisa" (Adorno, I980: I74). A crítica à valorização do gosto popular provinha da inundação dos diversos campos da atividade artística pela indústria cultural e do caráter ideológico da aceitação das obras, que favorecia o conformismo. Cohn (20I7: 248) esclarece:

Há aqui uma concepção muito específica de democracia no campo da cultura. Consiste ela em sustentar que a posição democrática nada tem a ver com a adulação das massas com seus gostos e preferências, mas com o desmascaramento do engodo a que são submetidas ao serem postas ideologicamente como sujeitos de um processo que precisamente só se sustenta como tal porque elas não têm como contestá-lo e como disputar a condição de sujeito de fato.

Segundo Cohn (2017: 244, 245), a discussão estética visava "expor a negatividade intrínseca às condições que critica, ao levá-las aos seus limites [...] e isto se faz em nome de potencialidades histórico-sociais concretas, cuja efetivação precisamente as condições e tendências dadas bloqueiam". Em sentido mais específico, o conceito de indústria cultural destinava-se a incluir as formas aparentemente mais inofensivas de regressão na satisfação cotidiana das massas e de produção simbólica como, por exemplo, no entretenimento e na música popular. Daí a ênfase de Adorno na recepção dos artefatos culturais e da cognição a eles associada.

Michael J. Thompson (2010) postula que a crítica de Adorno deve ser entendida em um contexto mais amplo, que envolve a produção musical em geral e a possibilidade de as obras de arte propiciarem, em seus aspectos formais, engajamento crítico ou conformismo. Destaca a influência hegeliana e a concepção da arte como forma de cognição no quadro do "processo de crescimento humano" (Thompson, 2010: 37-38), e a influência de Lukács pela possibilidade de desenvolvimento da consciência crítica nos marcos da estrutura social capitalista (Thompson, 2010: 47). Thompson refuta o pretenso elitismo de Adorno ao ressaltar que sua crítica estética relaciona as contradições da vida na modernidade com a recepção da produção musical e, um passo adiante, o alcance da arte em se opor à regressão conformista. Para Thompson (20 I o: 39), crítica estética e teoria social estão aí imbricadas pela valorização das "verdadeiras" obras de arte que sacodem as ilusões do status quo e carregam a promesse de bonheur de que o mundo poderia ser outro.

Thompson (2010) e Witkin (2000) lembram que Adorno veio a reconhecer a genialidade de Duke Ellington ou de Charlie Parker, mas considerava a música deles ideológica com elementos formais que definiam uma arte que em nada contribuía para o avanço do espírito crítico, em uma linguagem contaminada pelos mecanismos inerentes à indústria cultural. No entanto, vale assinalar que Adorno viveu até I 969 e durante décadas esteve exposto às mais diversas manifestações do jazz, incluídas as incursões de vanguarda e atonais que se diferenciaram da música comercial. 
Ao tratar das soluções tonais e harmônicas e da quebra dos ritmos na execução do jazz, Adorno concluiu que a "liberdade" do gênero era apenas uma máscara que disfarçava a sua "banalidade" (Thompson, 20 Io: 44). Seu argumento se concentrava na regularidade do ritmo mantida pelo baixo e pela bateria, o que desmentia sua "espontaneidade" e "dinamismo", e, em extensão, nas intervenções do solista, que mal se afastavam do esquema repetitivo. A "banalidade" se traduzia pela "estereotipia" (Thompson, 2010: 44) do que era aparentemente inventivo e inovador. Truques, fórmulas e clichês definiam a banalidade, que impedia os ouvintes de alcançar os aspectos formais mais complexos da música. Para Adorno, segundo Thompson, "jazz é incapaz de qualquer inovação musical em termos da natureza formal da linguagem musical" (Thompson, 2010: 46).

Adorno julgou ter percebido antecipações das harmonias do jazz na obra de Debussy, assim como Beethoven já fizera alterações de ritmo semelhantes ao gênero na "Sonata para piano op. I I I" (Thompson, 20I0: 46). Tais experimentos eram apenas recursos parciais para Debussy e Beethoven se lançarem em fulgurações mais amplas da criação musical. Assim, o jazz apenas reciclava aspectos da música séria, transportava seus ouvintes para o terreno do inalterado e banalizava os elementos das "verdadeiras obras de arte". Em "On jazz", pela popularização, o argumento fica acentuado quando escreve: "quanto mais democrático, pior o jazz se torna"2 (Adorno, I990: 50).

Uma observação do romancista e ensaísta inglês Geoff Dyer (2013: I96I97), em Todo aquele jazz, remete a uma percepção contrária:

Escrevendo sobre a sonata para piano "Appassionata", op. 57, de Beethoven, Theodor Adorno observa que "faz sentido pensar que o que primeiro ocorreu a Beethoven não foi o tema principal, como aparece na exposição, e sim sua variante principal, na coda, e que ele, por assim dizer, derivou retroativamente, o tema principal de sua variação". Algo muito semelhante ocorre com frequência no jazz: no decorrer de um solo, um músico executa momentaneamente, e quase por acidente, uma frase que pode tornar-se a base de uma nova composição, que também servirá de tema para improvisação - e esses solos podem, por sua vez, gerar outra frase que será desenvolvida numa composição. Os músicos de Duke Ellington viviam resmungando que um fragmento musical que haviam incluído num solo tinha sido notado por Duke e transformado numa música publicada como sendo de sua autoria - embora se apressassem a admitir que só uma pessoa com o gênio de Duke poderia apreender o potencial daquele fragmento e aproveitá-lo tão bem como ele.

No tratamento de Adorno, as variações da linguagem formal do jazz ficam confinadas em um terreno estreito, que as reduzem a "ornamentos" de pretensas inovações (Witkin, 2000: I46). Assim, muita coisa se perde. A banalidade atribuída à repetição não contempla a sucessão de invenções no improviso nem a interação entre os músicos, absolutamente decisivas para a criatividade presente no jazz. Ornette Coleman e Charles Mingus, apenas dois exemplos de um 
exército de talentos, desenvolveram um sem-número de batidas em tempos variados e flutuações rítmicas originais, além de soluções harmônicas inusitadas provenientes da comunhão musical de momento entre os integrantes de suas bandas.

Adorno rejeitava a diluição das linhas de demarcação entre o compositor e o executante, essa fonte inesgotável de inovação no jazz. A simbiose das funções entre o compositor e o executante não era compatível com a elaboração mais profunda das possibilidades da música e o impacto que poderia trazer para a recepção. Em seu entendimento, a composição escrita devia se sobrepor ao improviso, que Tanaka (20 I2: I43) caracteriza como fuga controlada. No entanto, a complexidade da música de Thelonius Monk não obedecia a tal princípio:

Se Monk tivesse construído uma ponte, teria eliminado os elementos considerados essenciais, até só restarem as partes decorativas, mas de alguma forma ele teria feito a ornamentação absorver as vigas de sustentação, de modo que era como se tudo estivesse construído em torno do que não estava presente. A ponte não deveria se sustentar, mas se sustentava, e o encanto vinha do fato de dar a impressão de que poderia ruir a qualquer momento, da mesma maneira que a música de Monk sempre parecia ameaçada de desmoronar (Dyer, 2013: 53-54).

Tais movimentos melódicos e rítmicos nada tinham de simples e solicitavam dos valores dos sentidos e dos valores do espírito mais do que o estado de distração. A música de Monk, Duke Ellington, Charlie Parker, Miles Davis, Coleman Hawkins, Charlie Mingus, John Coltrane, Bill Evans e de uma galeria infindável de gigantes do jazz transporta o ouvinte para regiões cujos horizontes descortinam mais do que a ambientação no fácil, no conhecido, no ligeiro. Todas essas contribuições permitiram aos ouvintes alcançar outros patamares de compreensão da música. Na obra de Adorno não há referências claras às fontes emocionais e intelectuais do jazz, como na descrição do que era mobilizado por Charlie Parker:

A emoção criada pelo jazz quando está acontecendo é tão inequivocamente diferente de quando o grupo está apenas tocando por tocar que partes inteiras do catálogo do jazz (e muitas apresentações ao vivo) empalidecem em comparação. Saber disso - sentir essa emoção - impõe aos músicos de jazz uma escalada íngreme e intimidante, sobretudo quando muito daquilo que constitui a grandeza do jazz se situa além do limite da técnica; sobretudo quando, como todos os músicos concordam, eles têm de pôr todo o seu ser no que estão tocando, quando a música depende da vivência deles, do que eles têm a oferecer como pessoa: "A música é sua própria experiência, seus pensamentos, seu conhecimento", disse Charlie Parker. "Se você não a viver, ela não vai sair de seu instrumento" (Dyer, 2013: 210).

Adorno tinha dúvidas sobre a autenticidade das raízes negras e africanas do jazz, sugerindo que seus elementos distintivos tinham sido adaptados às leis do mercado pela estandardização. Em "On Jazz", chegou a qualificá-lo como 
a música do corpo domesticado na escravidão, ou seja, uma nova forma de repressão, mascarada de passado e desprovida de qualquer vitalidade de origem (Witkin, 2000: I56).

No entanto, em I964, Martin Luther King, em seu discurso de abertura do Festival de Jazz de Berlim, destacou a luta dos negros pelos direitos civis, que encontrava paralelo na luta dos músicos de jazz para ter a sua arte reconhecida. Na ocasião, o reverendo King acentuou o papel desempenhado pela música ao articular "o sofrimento, as esperanças e as alegrias da experiência negra muito antes que a tarefa fosse assumida por escritores e poetas" (Dyer, 2013: 204-205). Longas séries de gerações haviam acumulado sofrimento e sensibilidade imbricadas na constituição do blues e do jazz.

Isso indica que a criação artística significativa de um tempo não emerge cativa da mercantilização, mas, de acordo com o potencial de vendas, a exploração econômica faz a sua parte. Se a perspectiva mercantil ocupar univocamente todo o campo da análise e interpretação dos fenômenos artísticos, pouco sobra para se apreciar do seu vigor estético e da recepção dos conteúdos envolvidos. Evidentemente a indústria estará sempre atenta às oportunidades, mas a expressão artística não é necessariamente diluída nas imposições da indústria cultural, como destaca Witkin: "cedo ou tarde, contudo, as possibilidades de invenção se esgotam, e a indústria cultural precisa retornar às fontes da criação estética autêntica que se encontram além de seus projetos"3 (Witkin, 2000: I65).

A rígida distinção entre música séria e música popular ligeira não acompanha o trânsito entre as linguagens e nas influências recíprocas capazes de alargar os limites até então existentes, que Witkin (2000: I68) chama de transmissão dos códigos da arte. Na música, se a produção artística de qualidade que sobrevive às determinações da indústria cultural for igualada à terra arrasada da "mera manipulação, pura lavagem cerebral e distração vazia", é como se nos tornássemos estranhos ao misterioso trabalho da memória, da imaginação e da carga de emoção despertada por tudo que não envolver a arte superior prescrita por Adorno . Na massificação da arte, nem sempre o público estará destinado a ser capturado pela banalidade e amar a sua cela porque impedido de amar outra coisa. Fredric Jameson (I994), marxista estudioso da obra de Adorno e da Escola de Frankfurt, argumenta que, de outra maneira, a crítica se igualará ao "domínio intemporal do juízo estético absoluto", de traços elitistas, calcado na valorização unilateral da alta cultura.

Em breve digressão, os Beatles ampliaram as possibilidades da música popular orientados pelo "quinto Beatle", o produtor e maestro George Martin, dotado de sólida cultura musical clássica. Nos anos I960, Paul McCartney escutava o trabalho de Karlheinz Stockhausen (para quem escreveu uma carta de fã), Pierre Schaeffer, Edgard Varèse, Ferruccio Busoni e Luciano Berio, músicos da vanguarda europeia. Na América, o eternamente irrequieto e crítico Frank Zappa (líder da banda Mothers of Invention) era um devoto de Stravinsky (Nor- 
man, 20I7: 220-22I). "Revolution 9", composta por John Lennon para o Álbum Branco dos Beatles, tinha nítida inspiração em Stockhausen (Norman, 2017: 32 I-322). No mesmo período, o consagrado maestro americano Leonard Bernstein fazia analogias entre o espírito universal das composições de Mahler e o disco Revolver, também dos Beatles. Em I99I, para comemorar os I50 anos da Orquestra Filarmônica de Liverpool, Paul McCartney compôs o "Oratório de Liverpool", uma peça clássica que levou dois anos e meio para ser concluída. O "Oratório" foi apresentado na Catedral Anglicana de Liverpool, cantado por Kiri Te Kanawa (considerada na época a melhor soprano do mundo), o tenor americano Jerry Hadley, o baixo barítono jamaicano Willard White e a meio-soprano sul-africana Sally Burguess (Norman, 2017: 6I6).

O Prêmio Nobel de Literatura concedido recentemente a Bob Dylan revela o reconhecimento ao talento e à maestria das letras dos sucessos cantarolados por gerações desde os anos i960. Os "livros" de Bob Dylan estão gravados nas faixas de seus discos e puderam ser alçados ao melhor da literatura. Portanto, as expressões da arte de massa não estão necessariamente condenadas à banalidade, nem ao deficit cognitivo de quem as aprecia. Esse é o tratamento conferido por Hobsbawm ao jazz.

\section{PARA ALÉM DOS PADRÕES DO MERCADO}

Eric Hobsbawm considera o jazz um dos fenômenos mais significativos da cultura mundial do século $\mathrm{XX}$, dotado de um extraordinário apelo, derivado do blues. Caracterizou-se também pela transferência diretamente para a música de emoções que, segundo Hobsbawm, nada tinham de regressivas, pois traduziam a experiência dos homens comuns. As manifestações iniciais do jazz, surgidas nos saloons do vale do Mississipi, desenvolveram-se a ponto de alcançar o patamar de "música popular da civilização urbana industrial" (Hobsbawm, 2009: 34). Hobsbawm apreciou o jazz como um estilo musical que trazia a história de um povo e se afirmou à revelia da cultura dominante.

Tem-se notícia de que os blues já existiam em I880, tocados em bares, bordéis, tabernas e casas de dança, para uma audiência de trabalhadores, marinheiros e gente sem ocupação definida. Seu padrão característico era o "canto e resposta", oriundos das canções de trabalho dos escravos no sul da América, além do comentário da vida cotidiana, algo reconhecível até hoje. A mistura de influências musicais, tendo os blues como o coração daquela linguagem, deu origem ao jazz, que se expandiu enormemente nas primeiras décadas do século XX. Esse nascimento se deu por volta de I900.

Nos anos I940, um milhão e meio de negros deixaram o sul na direção do norte e do oeste da América, integrando-se definitivamente à sociedade urbana e industrial, e levaram com eles suas preferências melódicas e rítmicas. Estava formado um novo nicho de mercado com notável expansão do jazz, e não se pode afirmar que tal fenômeno aconteceu à revelia da indústria fonográfica. 
Ainda assim, o que resultou não foi uma música padronizada ou destinada à produção em série. Segundo Hobsbawm, o espírito do jazz não favorece a repetição: os improvisos e as experiências harmônicas e rítmicas sempre deslocam a criação para um lugar além do previsível. O processamento comercial não diluiu o vigor do jazz, que por largos períodos não gozou de grande popularidade, nem esteve entre as apostas comerciais da indústria fonográfica. De acordo com Hobsbawm, trata-se de uma música sem linhas divisórias precisas e que carece até hoje de autoridades e instituições capazes de fazer com que as definições convencionais sejam respeitadas. Suas estruturas musicais derivaram das escalas originárias da África Ocidental misturadas às harmonias europeias, com ritmos que denotam vários tipos de síncopes (colocação de acento em uma batida normalmente não acentuada, ou supressão do acento em uma batida comumente forte). Seus instrumentos são incomuns na música erudita, provêm das mais diversas origens e se associam aos metais, às guitarras, ao contrabaixo, à bateria e ao piano, sem que haja um padrão das formações adequadas aos grupos e bandas. Desde o início, seus músicos autodidatas "fugiram às convenções há muito tempo sedimentadas pela música erudita europeia no que se refere à maneira 'correta' de utilizar instrumentos ou vozes educadas" (Hobsbawm, 2009: 50):

Sua voz é a voz comum, não educada, e seus instrumentos são tocados - até onde isso é possível - como se fossem essa vozes [...] Não há, no jazz, tons ilegítimos: o vibrato é tão legítimo quanto um som puro, tons "sujos" (dirty) tão legítimos quanto sons "limpos"... Os músicos de jazz são ainda grandes experimentadores, explorando até as últimas consequências os recursos técnicos de seus instrumentos, tentando, por exemplo, tocar trompete com a flexibilidade de um instrumento de madeira, ou trombone com registro de trompete. Essas obras, frequentemente de excessiva bravura artesanal, produzem suas próprias tonalidades não ortodoxas. Basicamente, porém, o jazz tem usado os instrumentos como vozes durante a maior parte de sua história. Como as vozes nas quais se baseiam os instrumentos e o que essas vozes tinham a dizer ou sentiam vinham de um determinado povo vivendo em certas condições, as cores do jazz tendem a pertencer a um espectro especial e reconhecível (Hobsbawm, 2009: 50-5I).

Essas vozes imprimiram um tipo de interpretação aos instrumentos, em fusão com escalas pentatônicas e a complexidade rítmica africana, adicionadas aos elementos musicais brancos e europeus. Do ponto de vista da experiência cotidiana, o jazz (e suas origens no blues) nasceu para resguardar das crueldades dos senhores da terra a integridade dos dominados. Em sua biografia, B.B. King recorda os relatos de sua avó, que contava ser o blues cantado pelos escravos das plantations do sul da América para avisar a chegada dos mestres nos campos. O recurso melódico tinha importância fundamental para os fugitivos, e em especial para as mulheres, porque o mestre podia tudo, incluindo violentá-las sexualmente. King percebeu então que o blues tinha a ver com sobrevivência (King \& Ritz, 2013: 7). O amálgama entre o sofrimento e as fontes variadas de expressão musical estão presentes na afirmação do jazz: 
O fator crucial para o desenvolvimento do jazz, bem como para toda música popular norte-americana, que contribuiu mais do que qualquer outro para o desenvolvimento forte e resistente da música folclórica em uma sociedade capitalista em rápida expansão, foi a sua não inundação por padrões culturais das classes superiores (Hobsbawm, 2009: 64).

O jazz é uma música de executantes em que a individualidade dos músicos está indissociada das fantasias musicais que podem surgir subitamente, sem preparação prévia. É muito difícil haver uma apresentação ou execução de um tema que seja exatamente igual a outra, a não ser em gravações em que o arranjador tenha um papel muito preponderante (como Duke Ellington ou Gil Evans). A improvisação dos músicos nos solos é determinante para o rumo a ser seguido na ambiência musical assim formada. No jazz há sempre espaço para algo que não foi tentado anteriormente, e limitá-lo às ingerências da indústria cultural como determinante para a sua afirmação é desconhecer a profusão de soluções artísticas que ele contém.

No canto, por exemplo, Billie Holiday imprimiu à voz humana junto ao microfone uma coloquialidade que definiu marca absolutamente singular. Louis Armstrong, um "gênio nato", "tinha o raro dom da inocência total que, por ler as emoções genuínas dos homens nas fórmulas fáceis das canções pop, pode até torná-las comoventes e totalmente convincentes" (Hobsbawm, 2009: I59). O jazz agregou influências e contribuições que alteraram o panorama da música americana no século XX e sacudiu a rigidez dos critérios de qualidade e autenticidade no "terreno minado" da música ligeira (na expressão de Adorno).

Iniciativas com pretensões de longo alcance de revolucionar o jazz também não estiveram imunes à comercialização, o que não diminuiu ou cancelou o peso de suas contribuições. Hobsbawm lembra, por exemplo, o bebop, originário de Nova York entre I 940 e I942, como "uma revolta dos músicos... uma revolta contra o público, bem como contra a submersão do músico em inundações de barulho comercial", com traços bem definidos em favor da igualdade do negro. Os músicos que figuraram nessa revolução passaram à história e são reconhecidos quando se trata das grandes inovações na música popular do século XX:

Os inventores dessa música revolucionária eram, sem exceção, jovens negros, a maioria com vinte e poucos anos, em grande parte ainda desconhecidos: John Birks (Dizzy) Gillespie, o trompetista; Charlie (Bird) Parker, o saxofonista; Thelonius Monk, o pianista; Kenny Clarke e Art Blakey, bateristas; Charlie Christian, guitarrista (o único que já era famoso); Bud Powell (piano); Milt Jackson (vibrafone); Tadd Cameron (arranjador); Max Roach (bateria); Kenny Dorham (trompete) e outros (Hobsbawm, 2009: II7).

O destino da criação dessa reunião de talentos não foi o desvirtuamento ou a diluição pela indústria cultural. Hobsbawm se estende sobre o fenômeno:

Estranhamente, porém, graças aos brancos, principalmente, pois a classe média negra não chegou a reconhecer o seu valor, as conquistas dos revolucionários 
do jazz foram logo reconhecidas. Os profissionais do comercialismo, sempre alertas para o valor material das novidades, fizeram do bop um slogan. Os jovens intelectuais brancos e boêmios, reconhecendo aí um mal-estar e uma revolta semelhante à sua própria, fizeram do jazz moderno a música da beat generation, o equivalente americano dos existencialistas europeus. As escolas de música, instituições e universidades, menos rígidas em razão da propaganda dos anos I930, estavam preparadas para reconhecer uma contribuição importante à cultura nativa americana, mesmo que vinda de uma fonte inesperada e "não respeitável". O próprio governo americano, ciente do valor propagandístico do jazz como produto de exportação cultural, enviou Dizzy Gillespie para o exterior como embaixador cultural exatamente da mesma maneira que fizera com Louis Armstrong anos antes (Hobsbawm, 2009: II9).

O jazz tinha uma história que prescindia de tais estímulos e seria igualmente reconhecido em qualquer país onde seus discos pudessem ser obtidos ou ouvidos livremente. As transformações revolucionárias na linguagem do jazz já estavam incorporadas, e, segundo Hobsbawm (2009: I04), “cada 'estilo' derivava de seu predecessor, modificando-o ou acrescentando algo a ele". Mesmo os músicos das big bands rapidamente se insatisfaziam com a repetição e a obrigação de tocar seguidamente as preferências do público. Eles só se viam estimulados pela emulação coletiva que os fazia dar o melhor de si. Para eles, lutar pela sobrevivência e fazer algum dinheiro nas apresentações das orquestras era uma coisa, tocar exercendo as suas energias criativas era outra.

Adorno criticou com aspereza a música proveniente das big bands que, segundo ele, apenas ofereciam entretenimento e oportunidade para a dança. No entanto, a história do jazz se fazia muito além desse terreno. Em "A indústria cultural: o esclarecimento como mistificação das massas", Adorno lamenta que a apresentação conjunta de Benny Goodman com o Quarteto de Budapeste tivesse influído no desempenho dos músicos clássicos e os tivesse conduzido a tocar de "maneira tão uniforme e adocicada como Guy Lombardo" (Adorno \& Horkheimer, I985: I 27). Lombardo foi um exemplo típico da massificação diluidora e vendeu milhões de discos com sua orquestra que adaptava tudo do repertório disponível que pudesse ser agradável à audição. O mais brilhante clarinetista do jazz, no entanto, talvez tenha sido Benny Goodman, cuja origem social estava nos projetos habitacionais de Chicago, onde moravam os brancos pobres. Rompeu as barreiras de cor juntando músicos negros e brancos em bandas e gravações, e tornou-se líder de uma orquestra que incendiava os salões. Goodman tem lugar no panteão do jazz em que figuram revolucionários dos instrumentos como os trompetes de Dizzy Gillespie e Miles Davis, o sax de Charlie Parker, a guitarra de Charlie Christian, entre outros.

Esses trajetos estão ausentes na reflexão de Adorno. O desenvolvimento e a expansão dessa linguagem musical pode ser resumida no refrão presente nas conversas dos revolucionários boppers: "Vamos tocar algo que eles não podem roubar, porque não podem tocar" (Hobsbawm, 2009: I I4). Um tanto dessa baga- 
gem pôde ser capturado ou diluído pela indústria cultural e suas quinquilharias musicais, mas o melhor já estava feito. Além disso, em vez da regressão, o jazz suscitou atenção, aprofundamento e reflexão em escala democratizante aos seus admiradores, que não ocupavam as posições mais altas na estrutura social:

(O jazz) produziu erudição e sérias discussões críticas a respeito de arte, entre pessoas que nunca poderiam ter sido levadas a isso pela arte ortodoxa: públicos que nos meios mais esnobes seriam chamados de "não os mais inteligentes do mundo", capazes de ouvir com total atenção, em silêncio absoluto, aos milhares, manifestações artísticas equivalentes a complexos recitais de música de câmara em termos ortodoxos; e mais, capazes de discuti-las como o público vienense de antigamente costumava discutir os méritos de um Furtwangler ou de um Bruno Walter. Foi a arte que mais perto chegou a derrubar as barreiras de classe (Hobsbawm, 2009: 33I).

O jazz proporcionou esse tipo de erudição às pessoas comuns, com seus níveis poderosos de conexão emocional junto com o exercício crítico de elaboração da música. Seus "príncipes", majoritariamente de origem nos setores subalternos da sociedade, reinavam nos ambientes seletos ou menos nobres dos bares e espeluncas, e proporcionavam aos seus iguais a identificação e a experiência de acesso a um gosto elevado na música. Do ponto de vista sociológico, tais identificações tiveram significado decisivo e, na música, se traduziram pela afirmação de um lugar e de aspirações dos homens comuns pouco reconhecidas no dia a dia da vida social:

No mundo do qual ele vem e onde ele trabalha, "entretenimento" (que significa qualquer talento pessoal ou dom vendido para o público ver, ouvir ou usufruir de alguma outra forma, do corpo para a alma) não é apenas uma forma de ganhar a vida, mas muito mais importante, uma maneira de se criar um caminho próprio dentro do mundo, só comparável ao crime ou à política, com a religião, do tipo vivido pelos próprios pobres para si mesmos, vindo um pouco atrás. É essencial lembrar disso. O músico, o dançarino, o cantor, o comediante, o boxeador ou o toureiro que alcançam o estrelato não fazem sucesso apenas no meio do público do esporte ou da arte em questão, mas são potenciais primeiros cidadãos de sua comunidade ou de seu povo. Um Caruso entre os pobres de Nápoles, uma Marie Loyd no East End londrino, uma Gracie Fields em Rochdale, um Jack Johnson, Joe Louis ou Sugar Ray no Harlem, um Louis Armstrong ocupam uma posição de muito maior importância entre o "seu" povo do que um Picasso ou uma Fonteyn na sociedade ortodoxa (Hobsbawm, 2009: 262-263).

Os príncipes do jazz simbolizavam uma "nobreza popular" e o acesso a uma erudição que pertencia às pessoas comuns, assim como afirmava um lugar de distinção nos abismos da desigualdade social. Em sua riqueza, o jazz, em constante aprimoramento artístico, se destacou como uma voz da grande massa de oprimidos da sociedade americana. Não esteve à parte da "indústria de entretenimento popular comum", no entanto realizou contribuições independentes que, por sua importância, forçaram as fronteiras da comercialização e ganharam destaque na expansão das linguagens musicais. A sofisticação al- 
cançada não deixou para trás as suas fontes, pois, como assinala Hobsbawm (2009: I 25), "o blues não é um estilo ou uma fase do jazz, mas um substrato permanente de todos os estilos; não é todo o jazz, mas é o seu núcleo".

As palavras de Eric Hobsbawm sobre a influência decisiva da indústria cultural praticamente se igualam às de Adorno. Mas, no tratamento conferido às manifestações da cultura popular, notadamente o jazz, há claras discrepâncias:

A cultura popular atual, nos países urbanizados e industrializados, consiste em entretenimento comercializado, padronizado e massificado, transmitido por meios de comunicação como a imprensa, a televisão, o cinema e o resto, e produzindo o empobrecimento cultural e a passividade: um povo de espectadores e ouvintes, que aceita coisas pré-empacotadas e pré-digeridas [...] Há uma boa dose de verdade bruta nessa afirmação. O problema é que tais generalizações deixam de lado tudo o que poderia nos ajudar a compreender o mundo do jazz e uma grande parcela dos problemas da cultura popular também (Hobsbawm, 2009: 39-40).

Em A história social do jazz é possível perceber, sem atenuantes, a crítica à supremacia da música degenerada pelo comércio. Enquanto Adorno manteve como referência as criações da vanguarda europeia da música erudita e as grandes obras da música clássica, Hobsbawm realçou o fenômeno cultural que nasceu das formas de expressão de contingentes dominados. Ao contrário da regressão da audição e da passividade, Hobsbawm, sem recusar o diagnóstico geral do fetichismo das mercadorias, valorizou os esforços abnegados daqueles que almejaram um lugar ao sol, desprovidos da intencionalidade de revolucionar a linguagem ou as formas de expressão consagradas na cultura dominante: "Como muitas vezes acontece na história das artes, as principais revoluções artísticas não surgem a partir dos que se intitulam revolucionários, mas daqueles que empregam as novidades com propósitos comerciais" (Hobsbawm, 2009: 22). A pesquisa do material histórico sobre o jazz, junto com as interpretações de Hobsbawm daí provenientes, desfaz a rigidez analítica que separa irremediavelmente a cultura de elite e a cultura de massa, pelo reconhecimento da qualidade de linguagens artísticas que resistiram às condições desiguais observadas na indústria cultural: "A história das artes não é uma única história, mas, em cada país, pelo menos duas: aquela das artes praticadas e usufruídas pela minoria rica, desocupada ou educada, e aquela das artes praticadas ou usufruídas pela massa de pessoas comuns" (Hobsbawm, 2009: 37).

As deformações e diluições próprias da indústria cultural não impediram que a criatividade do jazz e seus arrojos, que enriqueceram as linguagens musicais americanas, tenham ultrapassado as fronteiras dos guetos negros e popularizado novas formas de sentir e ouvir:

A democracia, a mídia de massa, ou o sentimento de nacionalidade levam o público minoritário a se conscientizar da tradição comum, e há formas de arte que, mesmo sem esse auxílio, são suficientemente poderosas para pressionar inexoravelmente sua entrada em território novo: o jazz é uma delas (Hobsbawm, 2009: 38). 
O mercado fonográfico estará sempre atento às fontes que permitem a expansão dos negócios e dos ganhos, venham elas de onde vierem. Nas condições capitalistas, é pouco provável que a criação popular seja conservada em seu estado puro; uma parte significativa será transformada em entretenimento comercial diluído:

As solicitações da cultura popular são, ao mesmo tempo, "comerciais" e "anticomerciais", embora pertençam a um esquema segundo o qual sempre que uma solicitação anticomercial se torna grande o suficiente (dentro das condições do capitalismo) ela passa automaticamente a ser comercial e a ser fornecida pela indústria com a maior intensidade possível, até ser diluída em papinha (Hobsbawm, 2009: 43-44).

Hobsbawm (2009: 4I) não se desfaz das implicações da indústria cultural quando destaca que "a indústria simplesmente descobre o que é mais lucrativo processar e processa". Os compositores e instrumentistas do jazz inovaram a criação musical mesmo que parte dessa tradição tenha servido às fórmulas comerciais de sucesso. O mercado não teria deixado escapar as oportunidades de lucro. No entanto, a afirmação das pretensões artísticas do jazz não obedeceu à dinâmica comercial:

O jazz, efetivamente, desenvolveu-se não só na linguagem básica da música popular, mas também como um tipo de música de arte sofisticada, que busca não só se fundir mas também competir com a música de arte estabelecida no mundo ocidental. Comparado a linguagens musicais que poderiam à primeira vista parecer da mesma ordem, ele não só alcançou sucesso muito maior como também é mais instável e bem mais ambicioso (Hosbawm, 2009: 35).

"Agradável num baile e horrível de ouvir" não faz justiça à propagação mundial do jazz. Um músico como Louis Armstrong, "um gênio nato, que intuitivamente organiza sua arte com a segurança automática com que as pessoas menos geniais respiram", era um homem extremamente simples, "pouco articulado mesmo, em termos de inteligência verbal", que passou à história como "a voz de seu povo falando por meio de um trompete" (Hobsbawm, 2009: I59). Armstrong elevou a música folclórica de New Orleans a um patamar de universalidade que a indústria cultural não foi capaz de diluir e transformar em "papinha". Os jazzistas de várias gerações foram mestres na capacidade de avançar por regiões harmônicas, melódicas e rítmicas que se diferenciaram de tudo o que havia sido realizado até então. Nessas aventuras havia de tudo: os músicos de bop gostavam de Bach, Schoenberg e Bartók. Thelonius Monk (apud Hobsbawm, 2009: 273) dizia "gostávamos de Ravel, Stravinsky, Debussy, Prokofieff, Schoenberg e talvez fôssemos um pouco influenciados por eles". Os experimentadores do free jazz, nem sempre agraciados com a popularidade, faziam incursões pela atonalidade e demonstravam absoluta indiferença com o sucesso comercial. Portanto, nada mais estranho ao jazz do que a reprodução 
do mesmo e a repetição que habitua os ouvidos à preferência pelo agradável, que constituem a base da regressão da audição.

\section{CONSIDERAÇÕES FINAIS}

A distância considerável entre as apreciações de Adorno e Hobsbawm envolve tanto a estrutura formal da música quanto a formação do gosto estético no quadro mais geral das relações sociais. A concepção de Adorno remete o jazz e suas estruturas de composição à satisfação de necessidades sempre iguais dos ouvidos acomodados na repetição. Mesmo os improvisos, essa fábrica de criatividade do jazz, são relegados a um roteiro sem surpresas, em que a suposta liberdade apenas disfarça a estereotipia. Apesar de reconhecer o talento dos instrumentistas, para Adorno a colorística do jazz (acentuada na performance das big bands, mas que pode ser estendida às demais formações) equivale à fragmentação do todo, isto é, aos momentos isolados de encantamento que nada exigem do ouvinte e impedem a elevação da audição. Nesse sentido, o jazz é situado nos limites da música ligeira e, portanto, incapaz de alcançar os padrões da música séria, além de reproduzir a parcialidade vivida nas relações sociais.

Hobsbawm, ao contrário, percebeu no jazz uma fonte de criação de vastas possibilidades. A partir do blues, o jazz renovou e transformou as linguagens da música popular e se tornou uma referência indispensável para músicos e compositores das mais diversas tendências. A história do jazz no século XX é uma história de ultrapassagem de limites, muitas vezes em trajeto autônomo e desvinculado das exigências do mercado fonográfico. Não havia garantias de que o cool jazz, por exemplo, em que se destacou Miles Davis, produziria grandes somas por discos vendidos. A sofisticação harmônica do jazz e a liberdade de criação de momento quando os músicos criavam seus improvisos produziram avanços e soluções muito além da caracterização da estandardização do gênero. O jazz se mostrou uma arte superior, ainda que Adorno tenha apontado corretamente a diluição musical representada na máquina de fazer dinheiro que foi a orquestra de Guy Lombardo.

A pesquisa de Hobsbawm permite ver que os "genuínos valores da cultura" (Adorno, I980: I69) não são uma exclusividade das vanguardas, nem a música ligeira o conduto fatal para a regressão e o conformismo das massas. Se as emanações da criatividade dos "de baixo" estivessem congeladas pela estratificação social ou sempre neutralizadas pela indústria cultural, somente um gosto estético "superior", incerta possibilidade a ser alcançada pelas maiorias e acima das manifestações culturais próprias de cada grupo ou classe social, seria capaz de ultrapassar os encantamentos artísticos "desvirtuados". Nesse sentido, muito da imaginação humana na arte fica silenciado. Ainda que sob a supremacia da degeneração comercial sistemática, o jazz conseguiu ultrapassar as barreiras de classe e enriquecer a cultura moderna com outras formas de 
510

expressão. O mercado e a indústria cultural podem cooptar a arte de mil maneiras, diluindo toda a afirmação enérgica da vida, porém o jazz e demais manifestações de origem popular que se tornaram parte de nossos prazeres estéticos mostram que isso é apenas parte da história.

Recebido em 23/8/20I8 | Revisto em 5/6/2019 | Aprovado em 9/7/2019

Luis Carlos Fridman é professor titular do Programa de Pós-Graduação em Sociologia da UFF, doutor em sociologia pelo Iuperj. Desenvolve pesquisas em teorias clássicas e contemporâneas da sociologia, sociologia da música e laços entre arte e política nos anos ig6o.

Publicou Vertigens pós-modernas - configurações institucionais contemporâneas, o jardim de Marx, e, como organizador, Socialismo - 


\section{NOTAS}

I No original: jazz is also incapable of any real musical innovations in terms of the formal nature of musical language.

2 No original: the more democratic jazz is, the worse it becomes.

3 No original: sooner or later, however, the possibilities of the invention are exhausted and culture industry must return to the sources of authentic aestethic creation that lie beyond the compass of its design initiative.

\section{REFERÊNCIAS BIBLIOGRÁFICAS}

Adorno, Theodor W. (I990). On jazz. Discourse: Journal for Theoretical Studies in Media and Culture, I2/I, p. 45-69.

Adorno, Theodor W. (I980). O fetichismo na música e a regressão da audição. In: Benjamin/Adorno/Horkheimer/Habermas. São Paulo: Abril Cultural (Os Pensadores).

Adorno, Theodor W. \& Horkheimer, Max. (I985). Dialética do esclarecimento. Rio de Janeiro: Jorge Zahar Editor.

Cohn, Gabriel. (20I7). Weber, Frankfurt - teoria e pensamento social I. Rio de Janeiro: Azougue Editorial.

Dyer, Geoff. (2013). Todo aquele jazz. São Paulo: Companhia das Letras.

Hobsbawm, Eric J. (2009). História social do jazz. São Paulo: Paz e Terra.

Jameson, Fredric. (I994). Reificação e utopia na cultura de massa. Crítica Marxista, São Paulo, I/I, p.I-25.

King, B.B. \& Ritz, David. (2013). B.B.King - uma vida de blues. São Paulo: Évora.

Norman, Philip. (2017). Paul McCartney. São Paulo: Companhia das Letras.

Tanaka, Elder Kôei Itikawa. (20I2). Adorno e o jazz. Crítica Cultural, Florianópolis, 7/I, p. I37-I48.

Thompson, Michael J. (2010). Th. W. Adorno defended against his critics and admirers: a defense of the critique of jazz. International Review of Aesthetics and Sociology of Music, New York, 4I/I, p. 37-49.

Witkin, Robert W. (2000). Why did Adorno "hate" jazz? Sociological Theory, Thousand Oaks, I8/I, p. I45-I70. 


\section{THEODOR ADORNO E ERIC HOBSBAWM} SOBRE O JAZZ

Resumo

$\mathrm{O}$ artigo traça um paralelo entre as concepções de Theodor Adorno e Eric Hobsbawm sobre o jazz e intenta uma crítica dos argumentos envolvidos nas concepções estéticas dos autores sobre o gênero musical. Na obra de Adorno, busca discutir o alcance do conceito de indústria cultural e suas considerações em torno do fetichismo e da regressão da audição, resultando em apreciações que ressaltam o caráter ideológico e os traços conformistas do jazz. O contraponto encontrado nos escritos de Hobsbawm destaca no jazz a ampliação das fronteiras no campo da música popular, imbricada às suas origens populares, e a elevação estética dos ouvintes.

\section{THEODOR ADORNO AND ERIC HOBSBAWM ON JAZZ}

Abstract

The article draws a parallel between the ideas of Theodor Adorno and Eric Hobsbawm of jazz and attempts to critique the arguments involved in the authors' aesthetic conceptions of this musical genre. In Adorno's work, it discusses the scope of the concept of culture industry and his considerations on fetishism and regression of hearing, which result in appreciations that emphasize jazz's ideological character and conformist traits. The counterpoint found in the writings of Hobsbawm emphasizes jazz's expanding of the borders of the field of popular music, intertwined with its popular origins, and the aesthetic elevation of its listeners.
Palavras-chave

Adorno;

Hobsbawm;

jazz;

regressão da audição;

cultura popular;

inovação musical.
Keywords
Adorno;
Hobsbawm;
jazz;
regression of hearing;
popular culture;
musical innovation. 